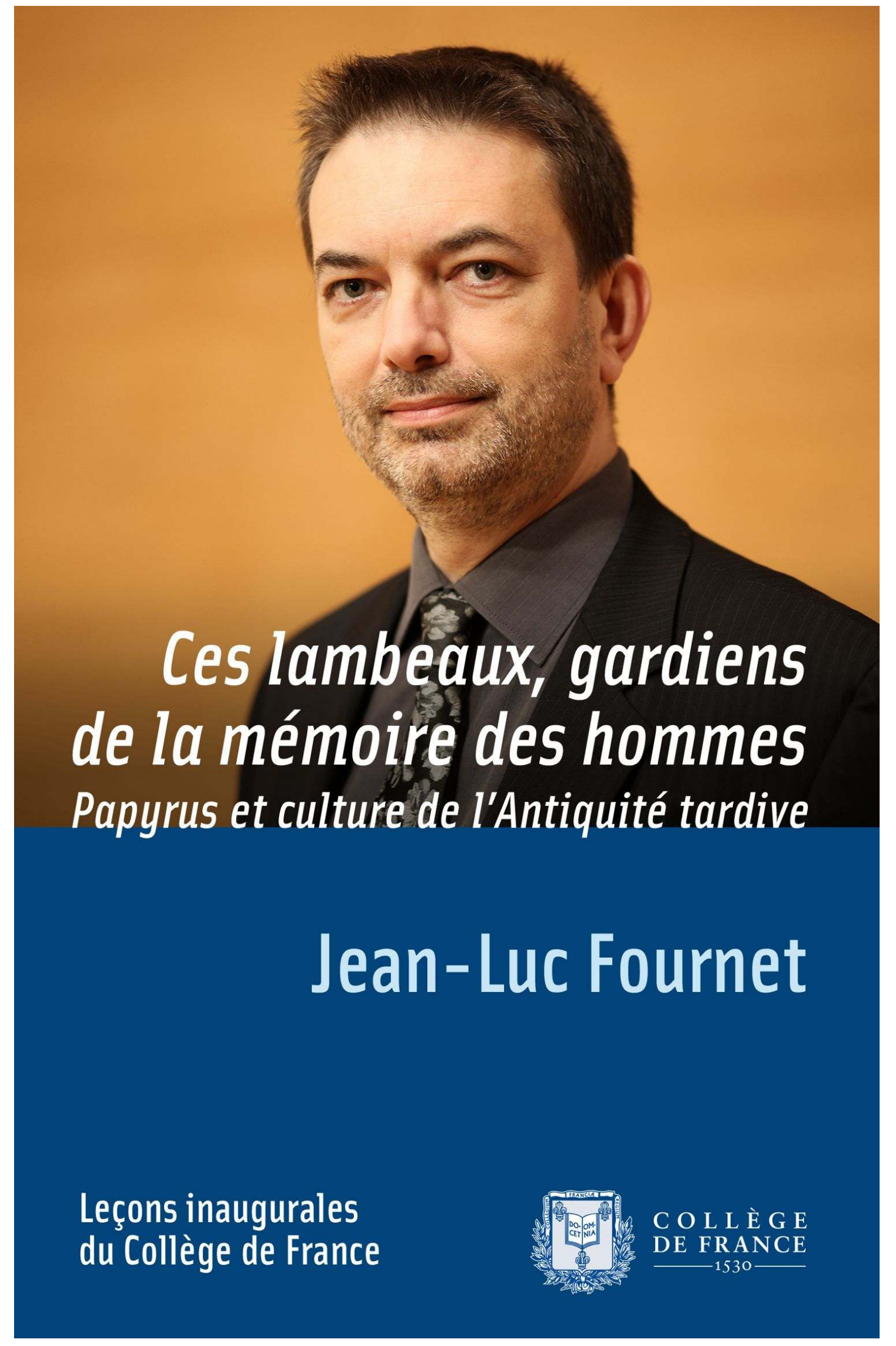




\section{Ces lambeaux, gardiens de la mémoire des hommes. Papyrus et culture de l'Antiquité tardive}

Leçon inaugurale prononcée le jeudi 7 janvier 2016

Jean-Luc Fournet

DOI : 10.4000/books.cdf.4794

Éditeur : Collège de France

Lieu d'édition : Paris

Année d'édition : 2016

Date de mise en ligne : 14 décembre 2016

Collection : Leçons inaugurales

ISBN électronique : 9782722604544

\section{Sboooks}

http://books.openedition.org

\section{Édition imprimée}

Date de publication : 15 juin 2016

ISBN : 9782213701271

Nombre de pages : 88

Ce document vous est offert par Collège de France

COLLEGE

DE FRANCE

Référence électronique

FOURNET, Jean-Luc. Ces lambeaux, gardiens de la mémoire des hommes. Papyrus et culture de l'Antiquité tardive : Leçon inaugurale prononcée le jeudi 7 janvier 2016. Nouvelle édition [en ligne]. Paris : Collège de France, 2016 (généré le 20 décembre 2017). Disponible sur Internet : <http://books.openedition.org/ cdf/4794>. ISBN : 9782722604544. DOI : 10.4000/books.cdf.4794.

Ce document a été généré automatiquement le 20 décembre 2017.

(c) Collège de France, 2016

Conditions d'utilisation :

http://www.openedition.org/6540 
Prenant son véritable essor au XIX ${ }^{\mathrm{e}}$ siècle avec la découverte de milliers de papyrus en Égypte, la papyrologie consiste à étudier les textes grecs et latins écrits sur un support transportable (papyrus, tessons de poterie, tablettes de bois ou parchemin). Alors que les inscriptions et les sources littéraires peuvent présenter une image normative, idéalisée ou parfois déformée des individus, les papyrus - aussi fragmentaires soient-ils - nous font entrer dans leur quotidien, rendant possible une archéologie de leurs pratiques culturelles. Tenter de déchiffrer «ces lambeaux, gardiens de la mémoire des hommes ", pour paraphraser Léonard de Vinci, tel est le défi du papyrologue, qui ne cesse ainsi de renouveler notre connaissance du passé.

\section{JEAN-LUC FOURNET}

Jean-Luc Fournet est papyrologue byzantiniste. Il a été membre de l'Institut français d'archéologie orientale du Caire, chargé de recherche au CNRS, puis directeur d'études en papyrologie grecque à l'École pratique des hautes études. En mars 2015, il a été nommé professeur au Collège de France, titulaire de la chaire «Culture écrite de l'Antiquité tardive et papyrologie byzantine ». 
SOMMAIRE

Introduction

Nicolas Grimal

Ces lambeaux, gardiens de la mémoire des hommes. Papyrus et culture de l'Antiquité tardive

Leçon inaugurale prononcée le jeudi 7 janvier 2016

Jean-Luc Fournet 


\title{
Introduction
}

\author{
Nicolas Grimal
}

1 Déjà en germes dans l'œuvre fondatrice de savants comme Jean Maspero ou Pierre Jouguet, les recherches en papyrologie byzantine se sont développées sous l'impulsion de grands papyrologues comme Roger Rémondon et, plus récemment, Jean Gascou. Le collègue que j'ai l'honneur de vous présenter ce soir est leur digne continuateur.

La papyrologie couvre un millénaire d'histoire - de l'arrivée d'Alexandre en 332 av. J.-C. à la conquête arabe en 642 apr. J.-C. Ce millénaire est à la fois celui de tous les devenirs possibles du monde antique et une mine de documents de toutes natures, dont le volume est incomparablement plus important que celui des œuvres littéraires qui nous sont parvenues. Le propre de la papyrologie est justement d'avoir orienté différemment et renouvelé l'approche que nous avons de cette période, longtemps considérée comme une sorte d'obscurité moyenâgeuse, au cours de laquelle les monothéismes émergents auraient tenté, au pire d'éradiquer, au mieux d'oublier la culture classique, dont notre propre histoire a fait, depuis la Renaissance, le modèle à suivre. Le parallèle avec le Moyen Âge occidental est d'autant plus pertinent que celui-ci n'est plus considéré aujourd'hui comme une période obscure, bien au contraire. Il en va de même de l'Antiquité tardive.

3 La charnière de l'ère chrétienne est ainsi le terreau d'une sédimentation progressive de cultures et de langues, à laquelle la domination chrétienne va ajouter une nouvelle strate, rejetant nombre d'acquis antiques et constituant une littérature propre, comme le feront à leur tour, à peine quelques siècle plus tard, l'islam et l'arabisation.

4 Ce qui nous apparaît ainsi aujourd'hui comme le résultat d'une évolution quasi linéaire n'a pas été sans recherches infructueuses ou constructions sans lendemain. Sur le plan religieux, l'Égypte des premiers temps de la chrétienté bouillonne d'une activité théologique intense, abritant aussi bien les grandes hérésies que le monachisme, développant en Moyenne-Égypte des écoles de pensée vigoureuses, dont les textes de Nag Hammadi - entre autres - nous ont transmis de nombreux éléments. On comprend, à les suivre, l'extraordinaire creuset que furent, non seulement l'Égypte, mais tout le Proche et le Moyen-Orient, dont toutes les cultures se repensent alors, de leur propre mouvement 
ou sous la contrainte, dans le cadre nouveau des monothéismes. Ce sont là les racines de ce Proche-Orient dramatiquement resurgi dans nos vies ces dernières années.

Les études byzantines - tout au moins l'école française - sont nées de l'enseignement d'esthétique et d'histoire de l'art que Gabriel Millet dispensa au Collège de France de 1926 à 1937. Puis, après la Seconde Guerre mondiale, son élève André Grabar enseigna pendant vingt ans, de 1946 à 1966, l'archéologie paléochrétienne et byzantine, fondant définitivement la discipline. Une chaire d'Histoire et civilisation du monde byzantin fut ensuite confiée, de 1975 à 2001, à Gilbert Dagron, qui fut également notre administrateur de 1997 à 2000. Le champ couvert par Gilbert Dagron étendait encore la discipline, étudiant aussi bien l'histoire et la civilisation de l'Empire byzantin, l'histoire urbaine de Constantinople aux IV et $\mathrm{v}^{\mathrm{e}}$ siècles, ou l'histoire de l'Asie mineure.

6 Sur ce fonds est né le projet d'une chaire consacrée à la "Culture écrite de l'Antiquité tardive et papyrologie byzantine", dont l'objectif est de renforcer durablement ces études à Paris et de les faire rayonner depuis le Collège de France. Il fallait pour cela un porteur capable de couvrir non seulement un vaste champ historique, de l'Antiquité tardive au Moyen Âge, mais aussi la discipline qui autorise de nouvelles synthèses, et qui n'a, jusqu'à présent, jamais été représentée au Collège de France : la papyrologie.

7 La formation et la carrière de Jean-Luc Fournet le destinaient à un tel rôle. Normalien, agrégé, ancien membre scientifique de l'Institut français d'archéologie orientale, directeur d'étude à l'École pratique des hautes études, il s'est formé auprès des meilleurs maîtres dans les langues et les domaines indispensables pour mener à bien le projet ambitieux qui est le sien: étudier l'interaction du monde classique et de l'Orient sur environ un millénaire, dans une région du monde où se sont élaborées les sources de la culture moderne.

Dans son abondante bibliographie - presque 200 publications, dont 7 ouvrages -, la linguistique et la paléographie tiennent le premier rang, c'est-à-dire tous les états de langue et d'écriture du grec à l'arabe, en passant entre autres par l'égyptien, le démotique et le copte.

9 Il sait aussi être homme de terrain, participant aux chantiers archéologiques avec autant de bonheur qu'aux entreprises scientifiques collectives, dont il est, bien souvent, l'animateur. Ses compétences lui ont valu un renom qui dépasse depuis longtemps les frontières de notre pays, et que les consultations internationales - devenues aujourd'hui pratique commune au Collège de France - ont largement confirmé, ainsi que des reconnaissances prestigieuses du CNRS et de l'Académie des inscriptions et belles-lettres, entre autres.

10 Aussi à l'aise dans l'étude des emprunts du grec à l'égyptien que dans les papyrus médicaux, les fragments poétiques de Théodore, la quête de nouveaux fragments d'Eschine, du pseudo-Isocrate, d'Homère, l'étude de la transmission de la culture grecque alexandrine, l'hagiographie chrétienne ou les textes documentaires, il ouvre largement sa recherche, au-delà de la constitution de corpora ou de l'édition de textes, à la culture de l'écrit, c'est-à-dire à l'étude de la paléographie et de la diplomatique en tant que porteuses de sens et inscrites dans le contexte culturel et institutionnel de chaque période.

11 La création de cette chaire vient à un moment où nous repensons et entreprenons de développer en un ensemble cohérent notre Institut des civilisations. Les études byzantines et la papyrologie doivent y conserver la place centrale qu'elles y occupent 
depuis de nombreuses années, dans une association fructueuse non seulement avec l'Institut de recherche et d'histoire des textes, l'École pratique des hautes études et les diverses universités, mais aussi avec les chaires du Collège de France consacrées à l'islam, au monde de la Bible, de la Grèce et de Rome, à l'assyriologie et à l'égyptologie.

\section{AUTEUR}

\section{NICOLAS GRIMAL}

Professeur au Collège de France, titulaire de chaire «Civilisation pharaonique : archéologie, philologie, histoire » 


\title{
Ces lambeaux, gardiens de la mémoire des hommes. Papyrus et culture de l'Antiquité tardive
}

Leçon inaugurale prononcée le jeudi 7 janvier 2016

\author{
Jean-Luc Fournet
}

Le cose disunite s'uniranno e riceveranno in sé tal virtù

che renderanno la persa memoria alli omini. Cioè $i$

palpiri che sono fatti di peli disuniti e tengano memoria

delle cosse e fatti delli omini.

« Les choses désunies s'uniront et acquerront la

faculté de rendre aux hommes leur mémoire perdue : ce sont les papyrus, qui sont faits de brins

désunis et gardent la mémoire des choses et des actions humaines. "

Léonard DE VINCI, Maximes, fables et devinettes

1 Monsieur l'Administrateur,

Monsieur l'Ambassadeur,

Messieurs les Présidents,

Chers collègues,

Chers amis,

Mesdames, Messieurs,

Il m'arrive de me demander ce que serait notre connaissance de l'art italien de la Renaissance si nous n'avions, pour en juger, que Les Vies des plus excellents peintres, sculpteurs et architectes de Giorgio Vasari, ouvrage certes essentiel pour l'histoire et l'historiographie de l'art, mais qui réduit la production artistique à une réalité de papier. Heureusement, nous avons conservé une partie des œuvres originales qui, avant de nous aider à comprendre ce mouvement artistique unique, nous permettent de l'appréhender dans la réalité et la diversité de ses formes. Eh bien, mutatis mutandis, la Renaissance sans les œuvres originales, c'est un peu ce à quoi serait condamné un historien de la culture 
antique sans les papyrus, "ces lambeaux, gardiens de la mémoire des hommes", pour paraphraser la saisissante définition que Léonard de Vinci en a donnée le premier dans l'Europe moderne. Personne n'oserait aujourd'hui nier l'apport des papyrus à notre connaissance de l'Antiquité et du début de l'époque byzantine. La nécessité de tenir compte des papyrus est pourtant une évidence qui a mis du temps à s'imposer en France. Ainsi le Collège de France, fidèle baromètre, depuis sa création, de la science en train de s'élaborer et de se réinventer, a-t-il attendu 2015 pour ouvrir sa première chaire de Papyrologie. Si je suis honoré d'en être le premier titulaire et si je remercie chaleureusement mes collègues de la confiance qu'ils m'ont accordée, il n'en reste pas moins vrai que ce retard est symptomatique d'une exception française qu'il n'est pas inintéressant de dégager et d'interpréter.

La papyrologie est la science des textes écrits avant tout en grec, langue devenue officielle avec les Ptolémées ${ }^{1}$, mais aussi en latin, et livrés essentiellement par les sables d'Égypte depuis la conquête gréco-macédonienne d'Alexandre le Grand en 332 av. J.-C. jusqu'à la fin du viII ${ }^{\mathrm{e}}$ siècle de notre ère (soit un siècle et demi après la conquête arabo-musulmane en 642, qui amorce le processus d'arabisation du pays). Elle ne traite pas de n'importe quels textes mais de ceux écrits à l'encre sur un support transportable : évidemment le papyrus (fabriqué à partir de la plante Cyperus papyrus L.), mais aussi les autres supports amovibles utilisés par les Anciens, comme les tessons de poterie (ostraca), les tablettes de bois, le parchemin, le cuir, etc., autant de supports qui s'opposent aux inscriptions gravées, faites pour rester en place et non pour circuler, et qui sont du ressort de l'épigraphie (fig. 1). Pendant longtemps, la papyrologie est restée, pour ainsi dire, prise en étau entre l'égyptologie et l'épigraphie grecque, deux disciplines avec lesquelles elle présente bien des points communs : l'aire géographique pour l'une, la langue et la culture de la civilisation étudiée pour l'autre. En inventant l'égyptologie au début du xix siècle, la France a rendu plus difficile l'éclosion de la papyrologie en accréditant l'idée, sûrement à son corps défendant, que l'Égypte - ou, en tout cas, celle qui était digne d'intérêt - était avant tout l'Égypte pharaonique. Elle ne pouvait pas être pionnière sur deux fronts à la fois. Toute l'activité scientifique qu'elle déploya sur le front égyptien s'est ainsi évertuée à faire renaître la « civilisation des hiéroglyphes » restés si longtemps muets, en laissant de côté plus d'un millénaire d'histoire grecque, qui l'a d'abord côtoyée dans ses derniers siècles, puis lui a survécu jusqu'à l'époque médiévale. 
Figure 1

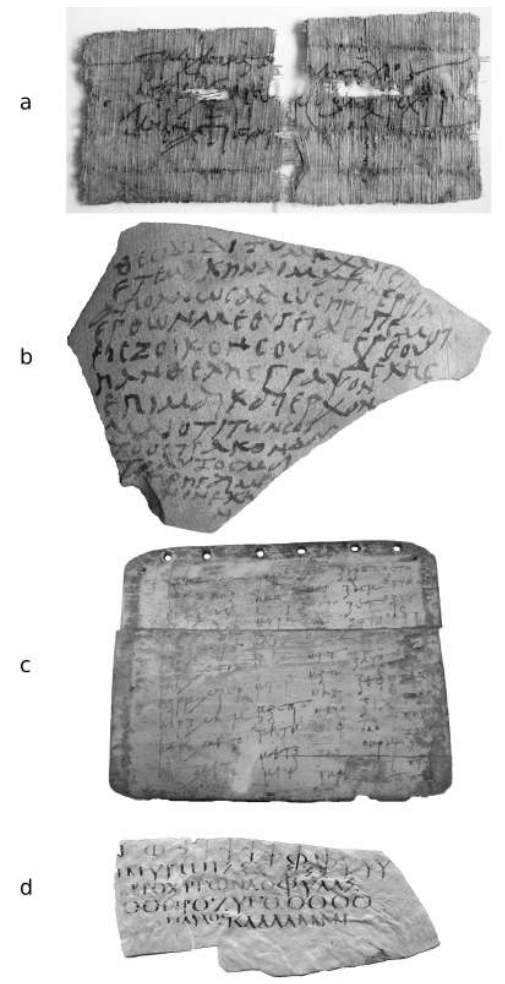

Les principaux supports de l'écrit qu'étudie le papyrologue : le papyrus, les tessons de poterie, les tablettes de bois, le parchemin ( C) collection particulière (a-b) ; Musée égyptien du Caire (c) ; Institut français d'archéologie orientale/IFAO (d).

Photographies : J.-L. Fournet.

En même temps se développait l'idée qu'en dehors de l'étude des manuscrits médiévaux qui, pendant quatre siècles, avait bordé leur horizon, les études classiques ne pouvaient se renouveler que par l'épigraphie. Le sort que celle-ci connut au Collège de France en est une belle illustration: elle fit son apparition officielle dès 1861 avec Léon Régnier, titulaire de la chaire d'Épigraphie et d'Antiquité romaine et, pour ce qui est plus spécifiquement de l'épigraphie grecque, en 1877 avec Paul Foucart, auquel succédèrent Maurice Holleaux en 1927, puis Louis Robert en 1939. On notera que ce dernier remplaça Émile Bourguet, titulaire de la chaire de Langue et littérature grecques - une des deux plus anciennes chaires du Collège de France - qui disparut pendant presque quarante ans jusqu'à ce qu'elle ne soit recréée pour Jacqueline de Romilly en 1973. Ainsi l'épigraphie at-elle été pendant plusieurs décennies la seule discipline relevant des études grecques présentes au Collège de France, celle qui symbolisait le renouvellement dans ce domaine. Elle y a été enseignée sans grande discontinuité jusqu'à Denis Knoepfler, qui a reçu il y a quelques mois son honesta missio au grand regret de tous.

Pourtant, la papyrologie aurait pu s'imposer plus vite en France, et cela précisément au Collège de France, grâce à l'une de ses grandes figures, aujourd'hui injustement méconnue. Helléniste complet, Antoine-Jean Letronne (fig. 2) a très vite fait de l'Égypte gréco-romaine le principal objet de ses recherches. Abandonnant la chaire de Morale et d'histoire à laquelle ses pairs du Collège de France l'avaient nommé en 1834, il succéda en 1837 à la chaire de Champollion, mort cinq ans plus tôt. Mais contrairement à son prédécesseur, c'est l'Égypte de langue grecque qui l'intéressait. L'étudiant principalement 
à travers ses inscriptions, il se lança dans l'entreprise d'un Recueil des inscriptions grecques et latines de l'Égypte, dont le premier volume sortit en 1842, après ses magistrales Recherches pour servir à l'histoire de l'Égypte pendant la domination des Grecs et des Romains, tirées des inscriptions grecques et latines relatives à la chronologie, à l'état des arts, aux usages civils et religieux de ce pays (Paris, 1823). Même si ces ouvrages ne font pas de place aux papyrus, Letronne s'est vite rendu compte de la nécessaire complémentarité entre épigraphie et papyrologie. Il est un des premiers en France à l'avoir compris et à avoir cherché à tirer profit des papyrus, comme le montre sa Lettre à M. Passalacqua sur un papyrus grec et sur quelques fragments de plusieurs papyrus appartenant à sa collection d'antiquités égyptiennes (Paris, 1826). Aussi est-ce à lui qu'en 1828 Auguste de Forbin, alors directeur général du musée du Louvre, demanda d'éditer les papyrus du musée Charles X, inauguré par Champollion l'année précédente. Letronne accepta. Il publia des papyrus de ce musée isolément en 1833 et en $1836^{2}$. Mais il meurt en 1848 : s'il a tout juste eu le temps de sortir le deuxième volume de son Recueil des inscriptions grecques et latines de l'Égypte, il laisse inachevée l'édition des papyrus qu'il prévoyait de publier après le troisième et dernier volume de son Recueil des inscriptions. Et surtout, il disparaissait sans avoir fait école dans ce domaine. Par sa connaissance de l'Égypte post-pharaonique, qu'il a contribué à mettre en lumière, et grâce à la méthode qu'il avait élaborée pour exploiter ces autres documents que sont les inscriptions, Letronne était alors le seul Français qui avait l'envergure et la curiosité intellectuelle nécessaires pour développer la papyrologie en tant que discipline académique. Ce fut donc, pour le Collège de France et la recherche française en général, un rendez-vous manqué alors même qu'en Europe commençaient à sortir les premiers recueils systématiques de documents papyrologiques. L'Italien Amedeo Peyron (1785-1870) publie en effet le premier volume des papyrus de Turin en 1827, suivi d'un second l'année d'après. Le Néerlandais Conrad Leemans (1809-1893) édite en 1843 les papyrus de Leyde. La publication posthume des papyrus du Louvre et de la Bibliothèque impériale réalisée par Wladimir Brunet de Presle (1809-1875) et par Émile Egger (1813-1885) à partir des notes de Letronne en 1865 (fig. 3) ne changea rien au manque d'intérêt du milieu académique français pour la papyrologie. Celle-ci continua à se développer lentement à l'étranger avant de connaître un soudain feu d'artifice dans la dernière décennie $d u \mathrm{xIx}^{\mathrm{e}}$ siècle, avec une série de fracassantes éditions britanniques et allemandes s'appuyant sur une politique volontariste d'achats et de fouilles. La France suivit le mouvement, mais avec un peu de retard, en la personne de Pierre Jouguet (1869-1949) qui, le premier, assit les études papyrologiques dans le monde universitaire de notre pays : il fut le premier Français à enseigner la papyrologie, d'abord à l'université de Lille, où il créa le premier institut français de papyrologie en 1903, puis à l'École pratique des hautes études de 1912 à 1927, enfin à l'Université de Paris de 1919 à 1933 ; il fut aussi le premier Français à mener des fouilles en Égypte, dont l'objectif principal était de découvrir des papyrus. Malgré les efforts de Jouguet, la papyrologie n'en restera pas moins chez nous une discipline assez marginale des études grecques. 
Figure 2

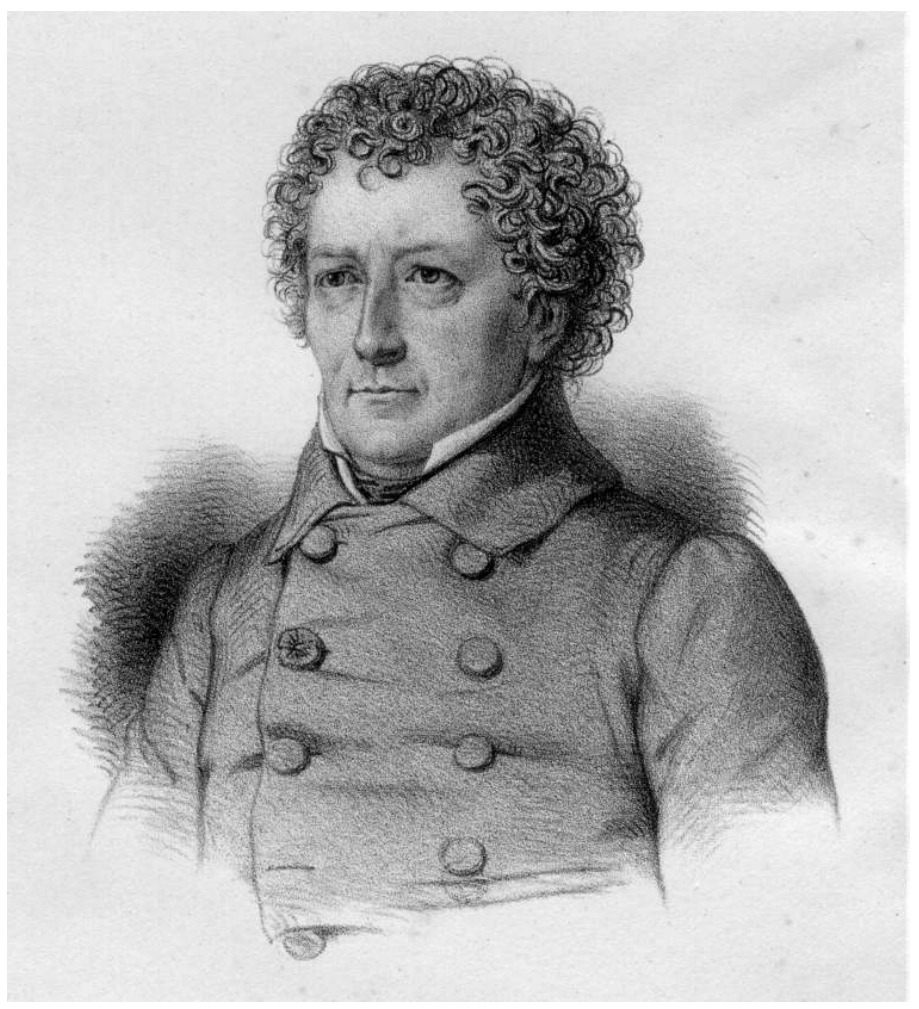

Antoine-Jean Letronne (1787-1848). 
NOTICES ET EXTRAITS

VANUSCRITS

DE LA BIBLIOTHÈQUE IMPÉRIALE

ET AUTRES BIBLIOTHEQQUES.

NOTICES ET TEXTES

DES PAPYRUS GRECS

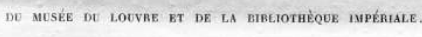

PUBLICATION PRÉPARÉE PAR FEt M. LETRONNE

EXTRAIT D'UN RAPPORT

L A A LACAdÉMIE des INSCRIPTIONS ET BELLLES-LETTRES. EN 1850

PAR M. W. BRLNET DE PRESLE.

Au milieu d'occupations multipliées, M. Letronne avait conçu le plan de plusieurs grands ouvrages dont il avait déjà fixé les points principaux, et qu'il ne cessait d'élaborer, tantôt la plume à la main. plus'souvent dans sa pensée, se confiant, pour les mener tous à bonne fin sur tes longues anées qui sendhient encore promires d son activité. Un de ces ouvrages dont il s'occupait avec prédilection, celui

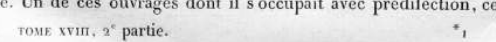

Le premier volume de papyrus jamais édité en France : les Notices et textes des papyrus grecs du musée du Louvre et de la Bibliothèque impériale par Letronne, Brunet de Presle et Egger, Paris, 1865.

Alors pourquoi ce désamour de la France pour la papyrologie? Outre qu'elle a souffert, comme je l'ai dit, du développement de l'égyptologie qui, par sa spectaculaire nouveauté, incarnait à elle seule les études sur l'Égypte, la papyrologie a pâti, me semble-t-il, au moment où elle commençait à se développer ailleurs, de la conjonction d'une propension de l'esprit français et d'une manifestation de l'histoire européenne.

Elle a pu heurter, en effet, une des caractéristiques du génie français : le goût pour la forme, qui se traduit notamment, dans le domaine de la langue, par le purisme, le respect de la norme. Si les quelques papyrus littéraires publiés au xix ${ }^{\mathrm{e}}$ siècle signalaient à l'attention du monde savant les potentialités des papyrus dans le domaine de la littérature grecque, il en allait autrement des documents, qui constituent l'écrasante majorité des papyrus et qui, écrits par des gens de toutes classes sociales, sans visée littéraire et à des époques éloignées des feux glorieux de l'hellénisme athénien, avaient de quoi dérouter les hellénistes en leur renvoyant une image déformée du grec auquel ils étaient habitués. Ils ne pouvaient que faire peur ou - pire - susciter l'indifférence ou le mépris, écrits qu'ils sont par des obscurs dans un grec truffé de fautes et de vulgarismes, contrevenant aux bonnes vieilles règles de l'atticisme, qui reste, je le rappelle, la norme $\mathrm{du}$ thème grec et encore trop souvent l'alpha et l'oméga de l'enseignement de la langue grecque dans nos universités - du moins pour celles qui ont encore la chance d'enseigner le grec...

8 Le reproche fait aux papyrus d'être écrits dans une langue barbare parcourt la plupart des travaux des quelques pionniers français qui ont osé s'aventurer dans ce nouveau champ. 
Ainsi l'éditeur du premier volume de papyrus français, Brunet de Presle, se sent-il obligé dans son avertissement de s'excuser auprès de ses collègues philologues :

Ils verront en effet que, indépendamment des lacunes qui ne permettaient pas toujours de saisir la liaison des idées, nous avions à reproduire certaines pages écrites avec la plus étrange négligence et souvent par des personnes à peu près illettrées. [...] Souvent aussi, il était difficile d'appliquer aux noms propres égyptiens les règles de l'accentuation grecque.

Eh oui, les premiers Français à s'intéresser aux papyrus ont été déroutés par une langue qui ne correspondait pas aux règles du grec apprises à l'école! Les inscriptions, elles, ne dépaysaient pas autant les philologues $\mathrm{du} \mathrm{XIX}^{\mathrm{e}}$ siècle puisque, destinées à la publicité, elles observent souvent une mise en forme plus soignée et sont rédigées dans une langue relativement châtiée.

9 Même les papyrus littéraires, qui, parce qu'ils reproduisent des textes du patrimoine grec, auraient dû échapper à ce reproche, ont été aussi à l'occasion englobés dans ce mépris très « vaugelasien ». Émile Egger, l'autre éditeur du premier volume de papyrus publié en France, dans une étude où il s'attache à montrer l'apport des papyrus d'Égypte, parle de la déception que produisirent finalement les premiers papyrus littéraires jamais exhumés à l'époque moderne, les papyrus philosophiques d'Herculanum : «Tant de métaphysique et de subtilité, s'écrit-il, que ne relève jamais le moindre charme du langage ${ }^{3}$. » Tout est dit.

10 Si se dessine souvent derrière ces critiques l'opposition entre l'Orient barbare et l'hellénisme fondateur de la civilisation occidentale - sur laquelle je reviendrai plus loin -, les préventions des philologues tiennent aussi et principalement à leur sensibilité linguistique de Français conditionnée depuis le XVII siècle par le culte du bon usage et rompue aux vertus du monolinguisme érigé en modèle culturel. Ce n'est pas un hasard si les premières publications papyrologiques, dans l'Europe du XIX $\mathrm{X}^{\mathrm{e}}$ siècle, sont dues à un Italien (Amedeo Peyron), à un Néerlandais (Conrad Leemans) et à un Allemand (August Boeckh ${ }^{4}$ ), autrement dit à des savants appartenant à des nations où le multilinguisme et le multidialectalisme portaient à une certaine tolérance linguistique bien éloignée du purisme vaugelasien.

11 Le désamour des philologues français du début du XIX ${ }^{e}$ siècle pour la papyrologie pourrait bien aussi avoir eu des causes plus conjoncturelles. Les années 1820, qui voient l'émergence de la papyrologie européenne, sont marquées en France par le développement du philhellénisme occasionné par la guerre d'indépendance grecque (1821-1832). Nombreuses sont les personnalités françaises à s'être enrôlées, intellectuellement ou parfois même physiquement, dans cette croisade pour les Grecs contre les Ottomans. Cette guerre eut des retombées idéologiques fortes en conférant une dimension ethnique à la notion d'hellénisme : alors que ce dernier englobait auparavant les ressortissants de l'ancien Empire grec, qui étaient loin d'être tous hellénophones, il devient désormais de plus en plus l'apanage des habitants de la Grèce proprement dite, de langue grecque. Cette nouvelle conception correspondait d'une certaine façon à la mutation politique des idées que Johann Joachim Winckelmann (1717-1768) avaient lancées dans le domaine de l'art, un peu plus d'un demi-siècle auparavant, avec son Histoire de l'art de l'Antiquités, où il exalte la Grèce en tant que patrie de l'art sublime, du bon goût, du beau idéal insurpassé, par opposition à un Orient de l'excès et de l'imperfection. Cette polarité se double à la faveur de la guerre d'indépendance d'une résonance religieuse: le christianisme (en l'occurrence orthodoxe), d'un côté, contre l'islam, de l'autre. En bref, ce conflit cristallise une opposition irréductible entre Occident 
et Orient, et rompt avec une longue tradition d'«orientalophilie» qui avait prévalu jusqu'au XVIII ${ }^{e}$ siècle dans les milieux intellectuels.

12 Or nos papyrus documentent un hellénisme oriental. Ils proviennent, qui plus est, d'un pays arabe qui avait perdu, chez les intellectuels, une partie de son aura après la débâcle de l'expédition d'Égypte (août 1801), dernier avatar de cette égyptophilie qui avait connu son point d'orgue au siècle des Lumières. Cette provenance a pendant longtemps fait peser sur eux la suspicion qu'ils étaient le produit d'un hellénisme barbarisé, contaminé par l'Orient, perverti par son multilinguisme et par son multiculturalisme. Cette prévention, qui pèsera lourd sur la destinée de la papyrologie en France, parcourt souterrainement maints travaux pendant encore une partie du $\mathrm{xx}^{\mathrm{e}}$ siècle. J'en veux pour preuve cette lettre, récemment éditée ${ }^{6}$, que Paul Perdrizet écrivit à Franz Cumont en 1919, dans laquelle il évoque sa participation au Congrès d'archéologie classique qui s'était tenu dix ans plus tôt au Caire :

J'enrageais de constater qu'aucun des hellénistes qui étaient rassemblés à cette occasion sur la terre d'Égypte n'eût l'idée de discriminer entre l'hellénisme \& l'Égypte: un disciple de l'hellénisme intégral ne doit approcher les superstitions égyptiennes qu'avec une sorte d'horreur. Ce n'est pas des égyptologues qu'il faut attendre le jugement parfait \& profond que l'histoire doit rendre sur l'Égypte : c'est à nous autres que cela revient.

Il écrivait la même année, avec son collègue Gustave Lefebvre, dans l'introduction aux Graffites grecs du Memnonion d'Abydos:

La médecine grecque, au contact des superstitions égyptiennes, s'était pervertie : elle oubliait le rationalisme d'Hippocrate pour les absurdités de Néchepso et d'Hermès-Trismégiste : ah! qui dira les torts de l'Égypte et les maladies qu'elle a passées à l'hellénisme...

Ces formules, qui font maintenant sourire, posent le problème plus fondamental de la représentativité de la documentation grecque d'Égypte. Car, pour que les papyrus soient considérés comme indispensables à notre connaissance de l'hellénisme antique et byzantin - postulat que j'ai posé au début de cette leçon--, encore faut-il qu'ils soient représentatifs de la culture qu'ils sont censés documenter. Ce n'est pas parce que les quelque 70000 papyrus d'Égypte viennent compenser pour une part la disparition de ceux qu'ont produits les régions moins périphériques de l'Empire romain ou byzantin, comme Rome ou Constantinople, et dont les conditions climatiques n'ont pas permis la conservation, que les données qu'ils livrent sont nécessairement généralisables à l'ensemble des territoires de ces empires dont l'Égypte a fait partie. On s'est en effet depuis longtemps demandé si l'Égypte n'était pas une exception institutionnelle, économique ou culturelle dans le monde gréco-romain. Même sans conclure de façon aussi extrême, on doit s'attendre à ce que se soient développés des particularismes locaux induits par le substrat égyptien et par les réalités géographiques tout à fait spécifiques (notamment les fameuses crues du Nil qui façonnent le paysage et conditionnent son agriculture). Quelle est la part du particulier par rapport au généralisable? Comment même distinguer l'un de l'autre? Peut-on suivre Ernest Babelon lorsqu'il disait, dans son allocution du Congrès d'archéologie classique du Caire de 1909 dont j'ai parlé plus haut: «Ce n'est pourtant pas l'Égypte égyptisante que nous sommes venus admirer et glorifier, 
comme l'a fait, à la suite de l'expédition de Bonaparte, le XIX siècle tout entier. Nous sommes venus pour contempler [...] la parure classique de littérature, de poésie et d'art dont les Grecs et les Romains avaient orné la vallée du Nil et que celle-ci a précieusement gardée, comme l'aïeule conserve avec tendresse les cadeaux de ses petits-enfants »? C'est pourtant dans ces interrogations que se joue le statut de la papyrologie en tant que science de l'Antiquité. La question de savoir s'il est légitime d'extrapoler les données égyptiennes à l'ensemble du monde gréco-romain a reçu des réponses variées selon les époques et la personnalité (parfois l'idéologie) de ceux qui y répondaient. La tendance actuelle serait même à minimiser les particularismes égyptiens. Mais il est en tout cas une période et un domaine dans lesquels la papyrologie a la vocation légitime de transcender les limites géographiques des textes dont elle s'occupe.

Cette période est celle de l'Antiquité tardive. L'Égypte est alors mieux que jamais intégrée au reste de l'Empire. D'un point de vue administratif, cette intégration, inaugurée avec son rattachement à l'Empire romain en 30 av. J.-C., s'est accélérée avec les réformes de Dioclétien et du fait de la position désormais exclusive du droit romain qui a laminé les droits locaux, et cela jusqu'à ce qu'elle ne se détache de l'Empire byzantin avec la conquête arabe en 642. Le christianisme, malgré les querelles théologiques qui ont secoué et divisé l'Empire, a lui aussi contribué à une plus forte intégration de cette province, en faisant notamment disparaitre maintes spécificités égyptiennes remontant à des traditions religieuses pharaoniques. C'est donc une période de koinè - pour éviter le mot, si suspect de nos jours, de globalisation - politique, religieuse et culturelle pendant laquelle les papyrus égyptiens ont le plus de chance d'être représentatifs de la situation extra-égyptienne ou d'offrir des renseignements directement exploitables pour l'étude du reste de l'Empire.

L'intérêt des papyrus est d'ailleurs moins de confirmer ou de compléter nos connaissances qui, dans le domaine institutionnel, s'appuient avant tout sur les inscriptions et les sources législatives (droit impérial, droit canon), que de montrer la mise en pratique des normes connues par ces textes, ce que seuls les papyrus d'Égypte sont à même de faire puisqu'une documentation de cette nature n'apparaît pas à Byzance avant le $\mathrm{XI}^{\mathrm{e}}$ siècle, et encore s'y restreint-elle à des milieux exclusivement monastiques. S'il y a souvent coïncidences ou rencontres, n'en apparaissent pas moins de nombreux décalages qui font tout l'intérêt de cette forme de documentation. La papyrologie pourrait même être définie comme l'art d'interpréter les décalages: décalages entre norme et pratique, entre centre et périphérie, entre innovation et continuité de la tradition. Ces décalages, s'ils existent dans toute société, ne sont documentés que par des sources de nature plus éphémère et à visée personnelle comme les documents de la pratique. Il peut s'agir de décalages chronologiques, par exemple entre la promulgation de la loi et son application, ou - plus intéressant-d'aménagements ou de contournements de la loi au nom de coutumes, d'habitudes ou d'intérêts contraires. Le papyrologue est appelé à nuancer ce que les sources législatives ou épigraphiques peuvent avoir de trop normatif, injonctif ou théorique pour se faire homme de terrain, anthropologue des pratiques sociales. Ce n'est pas l'homme tel qu'il veut se montrer qu'il sonde, mais l'homme tel qu'il est.

Les décalages ne s'observent pas seulement dans ce que nous disent les papyrus, mais aussi dans la façon dont ils nous le disent, autrement dit dans leur forme et dans leur langue. Le papyrologue doit sans cesse traquer les discordances qui existent entre la chose dite et la réalité. Il doit, par exemple, savoir éclairer sous son vrai jour tel contrat 
de prêt qui cache en fait une transaction matrimoniale, tel contrat de nourrice ou de vente qui masque un prêt, tel contrat de location qui dissimule une vente ou une donation. Les mots utilisés peuvent aussi être traitres, et le papyrologue doit sans cesse éviter de tomber dans le piège de l'acception naturelle. Ainsi, grâce au volume et à la répétitivité de la documentation, a-t-on pu déjouer le sens premier des expressions comme apatôr (litt. "sans père »), qui ne désigne pas un orphelin, mais l'enfant d'un soldat né pendant son service, ou " Perse de la descendance ", qui n'a rien à voir avec une ascendance perse, mais finit par devenir une pure fiction juridique appliquée, dans les contrats de prêt, à toute personne contractant une dette; on a pu comprendre que les symmachoi (litt. "qui se battent avec, alliés ») étaient des coursiers et que les exôpylitai (litt. « ceux qui sont hors des portes ») ou les allophylai (litt. « étrangers ») désignaient des fossoyeurs. Je me suis récemment aperçu, en comparant des inventaires d'églises sur papyrus et des récits hagiographiques coptes et arabes, que le banal mot trapeza, « table», d'où "autel », avait pris à l'époque tardive le sens de "patène ». De fait, quand les hagiographes nous relatent des vols de trapeza commis par des malfaiteurs dans des églises, il ne faut pas s'imaginer, comme on l'a cru, que les voleurs partaient avec la table d'autel sous le bras - ce qui n'aurait pas été chose aisée !-, mais tout simplement avec les objets liturgiques, souvent en métal précieux. Nombre de termes de l'administration ou de la fiscalité ont également acquis des significations difficiles à déduire de leur étymologie ou de leur sens traditionnel. Aussi est-ce une des grandes leçons de la papyrologie que d'inviter toujours à se défier des sens obvies et à refuser a priori de prendre les mots au pied de la lettre.

17 Les papyrus font plus qu'offrir un point de vue différent par rapport aux autres sources en corrigeant la perspective ou en rétablissant une information que celles-ci ne peuvent ou ne doivent dire, ils livrent leur lot de nouveautés : que ce soient des œuvres inconnues transmises par les seuls papyrus, que ce soient des faits nouveaux révélés par tels documents ou encore des mots ou expressions qui n'étaient jusqu'ici pas attestés par les autres sources. En cela, le papyrologue a toujours du nouveau à apporter, comme j'essaierai de le montrer dans mon enseignement en mettant à profit les nombreux inédits que j'ai pu rassembler ces dernières années et ceux que j'espère découvrir dans le futur ou - ce qui équivaut à les redécouvrir - en revisitant des papyrus mal lus, mal compris ou auxquels on peut raccorder de nouveaux fragments provenant d'autres collections qui en changent le sens - comme ce feuillet d'une édition d'Aristophane du IV siècle que j'ai pu reconstituer à partir de fragments conservés à Paris et à Oxford (fig. 4). 
Figure 4

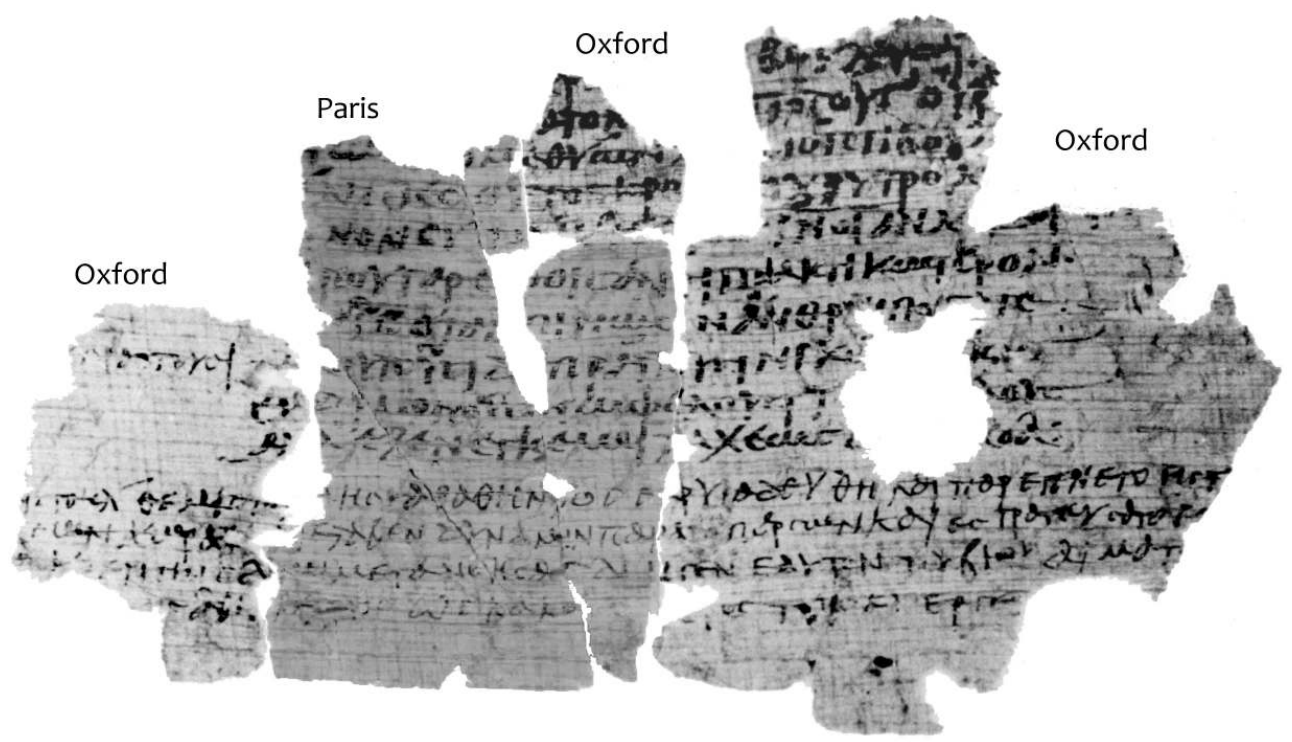

La papyrologie comme puzzle : un feuillet d'une édition d'Aristophane réduit à l'état de fragments partagés entre l'Institut de France (Paris) et la Bibliothèque bodléienne (Oxford). Source : Commentaria et lexica graeca in papyris, Pars I, vol. 1, fasc. 4, tab. II.

Et cette complémentarité des papyrus par rapport aux autres sources de l'historien ou du philologue est particulièrement efficiente, je l'ai dit, pour la période de la fin de l'Antiquité et le début de l'époque byzantine. C'est pourtant une époque qui a été longtemps négligée, sinon par l'école viennoise, qui a pu très tôt bénéficier d'une très riche collection de papyrus en grande partie d'époque byzantine et arabe, et par l'école française : si cette dernière a mis du temps à comprendre tout l'intérêt des papyrus, elle a cependant su rattraper son retard et se distinguer dans le domaine de la papyrologie byzantine grâce à trois figures à qui je me plais à rendre hommage ce soir : Jean Maspero (fig. 5), dont l'édition des Papyrus grecs d'époque byzantine du musée du Caire ${ }^{7}$ a ouvert la voie et dont l'œuvre aurait été plus marquante encore s'il n'était mort sur le champ de bataille à l'âge de vingt-neuf ans; Roger Rémondon (1923-1971) qui, par son enseignement à l'École pratique des hautes études, a fait école non seulement en France, mais aussi à l'étranger ; enfin, son élève, et mon maître, Jean Gascou, sans qui je ne serais pas ce soir devant vous et qui, par la densité de sa réflexion et l'originalité de son questionnement, a porté la discipline à un degré de maturité qui fait honneur à la recherche française. La papyrologie byzantine n'aurait d'ailleurs probablement pas pu se développer sans l'appui des grands byzantinistes français, qui ont su très tôt deviner les potentialités des papyrus pour leur domaine: Charles Diehl (1859-1944) a orienté Germaine Rouillard (1888-1946) dans la voie de la papyrologie en dirigeant sa thèse sur l'administration civile de l'Égypte byzantine ${ }^{8}$, ouvrage publié en 1923 qui formait un diptyque avec la monographie de Jean Maspero sur l'organisation militaire de l'Égypte byzantine $^{9}$; plus tard, Paul Lemerle (1903-1989), professeur au Collège de France de 1967 à 1973, qui se forma lui-même à la papyrologie à l'École pratique des hautes études et dont l'intérêt pour les papyrus est démontré, entre autres, par le fait qu'il inaugura sa nouvelle collection "Traité d'études byzantines » avec l'ouvrage d'André Bataille sur les papyrus $^{10}$; enfin, son successeur au Collège de France, de 1975 à 2001, Gilbert Dagron (1932-2015), qui favorisa le développement des études papyrologiques dans l'équipe qu'il 
dirigeait, le Centre d'histoire et de civilisation de Byzance, où j'ai été nommé à mon entrée au Centre national de la recherche scientifique (CNRS). Je souhaite ce soir rendre hommage à ce maître qui nous a quittés cet été en lui dédiant cette leçon inaugurale, modeste témoignage de ma reconnaissance pour sa bienveillance et de mon admiration pour son œuvre, si marquante que le monde des études byzantines se sent aujourd'hui bien orphelin.

Figure 5

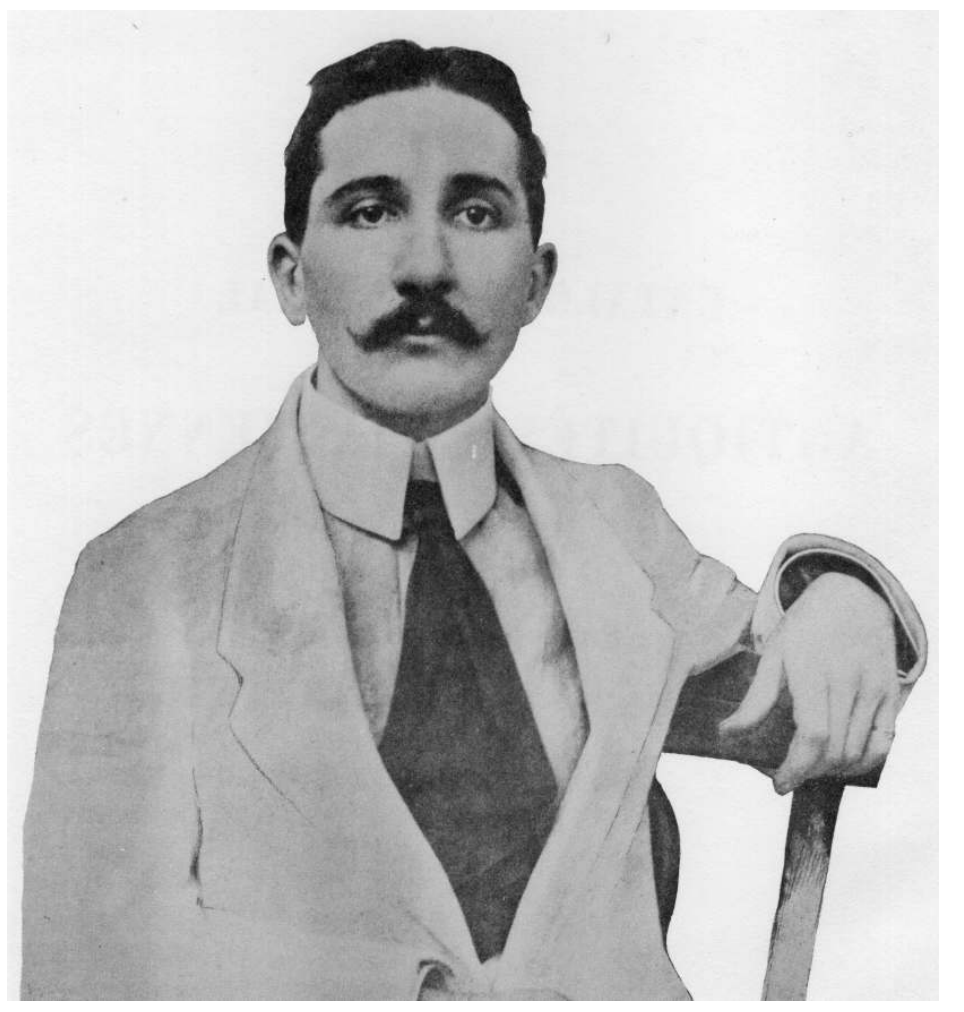

Le pionnier de la papyrologie byzantine en France : Jean Maspero (1885-1915).

19 Il faut malgré tout reconnaître que, pendant longtemps, la papyrologie byzantine a souffert des préjugés qui entouraient le Bas-Empire (terme qu'on n'ose plus utiliser aujourd'hui au nom du «linguistiquement correct»), préjugés au nom desquels cette période était stigmatisée comme décadente et annonciatrice des siècles «obscurs » (sic) du Moyen Âge. On en est revenu, depuis une quarantaine d'années (et les noms que j'ai cités à l'instant y ont grandement contribué). L'engouement pour ce qui est appelé maintenant l'Antiquité tardive s'est même intensifié ces dernières années, si l'on en juge par la bibliographie de plus en plus pléthorique. La sensibilité aiguë de notre époque pour les phénomènes de transition, les périodes de mutation, n'est pas pour rien dans la faveur que connaît l'Antiquité tardive. C'est en effet pendant celle-ci que s'est jouée, entre autres, la survivance de la culture grecque à la suite de choix qui ont été faits parmi les œuvres du patrimoine littéraire; que s'est développé un nouveau rapport à la culture écrite ; qu'ont été adoptées ou élaborées de nouvelles modalités de lecture et d'écriture (avec le codex et plus tard la minuscule ${ }^{11}$ ) ayant profondément marqué la transmission des textes et, plus largement, la culture de l'écrit jusqu'à nos jours. C'est enfin une période pour laquelle on dispose encore de sources à la fois abondantes et, pour une part, 
toujours inédites ou mal étudiées, contrairement aux périodes précédentes, ce qui ne peut manquer d'attiser la curiosité des chercheurs.

Ce regain d'intérêt, a bien sûr, considérablement stimulé la papyrologie byzantine, qui a vu depuis trente ans l'émergence d'une nouvelle génération. Les découvertes ou les publications récentes de papyrus provenant d'autres pays, du Proche et du Moyen-Orient (du désert de Judée, de Massada, de Pétra ou du Moyen-Euphrate), en désenclavant la papyrologie de l'aire égyptienne, en font une discipline sans cesse plus large et plus utile pour l'historien de la fin de l'Antiquité et de Byzance. Tout cela s'est traduit ces dernières années par une augmentation sans précédent de l'activité éditoriale, pratiquée par un nombre toujours croissant de papyrologues. Mais si la base documentaire s'élargit grâce à la publication de nouveaux volumes de papyrus, force est de constater malgré tout qu'il y a encore fort à faire du côté de la réflexion et de la mise en perspective des données textuelles. Des domaines aussi fondamentaux que les institutions et la pratique judiciaires, par exemple, sont encore en friche (les synthèses s'arrêtent à Dioclétien) : c'est un sujet que je compte mettre au programme de mes cours ces prochaines années. Il en va de même de la culture écrite, qui mérite d'être davantage étudiée, et surtout étudiée autrement.

21 La culture écrite est précisément le domaine dans lequel la papyrologie, comme je l'annonçais tout à l'heure, a vocation à jouer un rôle qui ne se confine pas à l'Égypte, en livrant des données extrapolables à l'ensemble de l'Orient grec. Et encore n'est-elle pas étudiée de la même façon selon le type de papyrus auquel on a affaire. Il est en effet usuel de classer les sources papyrologiques en deux catégories : les papyrus littéraires, qui sont les livres de l'Antiquité (actuellement environ 10000 unités éditées), et les papyrus documentaires, qui sont les textes de la vie de tous les jours, aussi bien publique que privée (quelque 60000 unités éditées). Chacune de ces catégories témoigne à sa façon de la culture écrite des Anciens, quoique selon des approches différentes et de plus en plus souvent étudiées par des chercheurs qui se spécialisent dans l'une ou l'autre.

C'est dans le champ de la papyrologie littéraire que les attentes des historiens de la culture sont a priori les plus fortes. On sait en effet combien notre connaissance de la littérature classique a été renouvelée par la découverte, dès la fin du XIX ${ }^{e}$ siècle, de papyrus contenant des œuvres que la tradition manuscrite byzantine n'avait pas conservées. Que saurait-on de Ménandre, de Bacchylide, d'Hérondas, de tels discours d'Hypéride, de certaines tragédies de Sophocle ou d'Euripide, sans les papyrus littéraires? Ces dernières années ont encore apporté leur lot de découvertes retentissantes avec la résurrection des livres I et II de la Physique du philosophe présocratique Empédocle; des épigrammes du poète Posidippe de Pella, qui fit carrière à la cour des Ptolémées; d'une partie de la Géographie d'Artémidore d'Éphèse (ou d'un texte qui en dérive), illustrée d'une carte géographique (la plus ancienne connue sur un papyrus grec) et qui servit ultérieurement de cahier de brouillon à des artistes; d'un codex d'épigrammes, dont au moins une partie sont de Palladas ; enfin de deux poèmes de Sappho $^{12}$. J'arrête là cette liste volontairement sélective (car chaque volume de papyrus apporte son lot de nouveautés) : c'est en effet l'aspect peut-être le plus connu, l'apport le 
plus incontestable de cette discipline aux yeux d'un plus large public. C'est aussi le plus aléatoire puisqu'il est totalement soumis au hasard des découvertes, sur le terrain ou dans les collections.

Mais un papyrus littéraire ne parle pas que par son contenu : il se livre aussi par la forme qui est la sienne. C'est le second enseignement, moins immédiat, des papyrus littéraires que de nous permettre une archéologie des pratiques lettrées de l'Antiquité : comment écrivait-on de la littérature, comment la lisait-on ? Les papyrus littéraires sont en effet les seuls - par les écritures qu'ils présentent, par leur bibliologie, par leur mise en page - à pouvoir apporter les informations qui nous manquent dans le reste du monde grec sur la forme des livres antiques et protobyzantins (et qui nous sont à nouveau disponibles pour des époques plus récentes). D'aucuns penseront que cet apport se limite à des considérations purement formelles, sans portée réelle sur le contenu même de la culture que ces papyrus aident à reconstituer. Un exemple les détrompera.

\section{Figure 6}

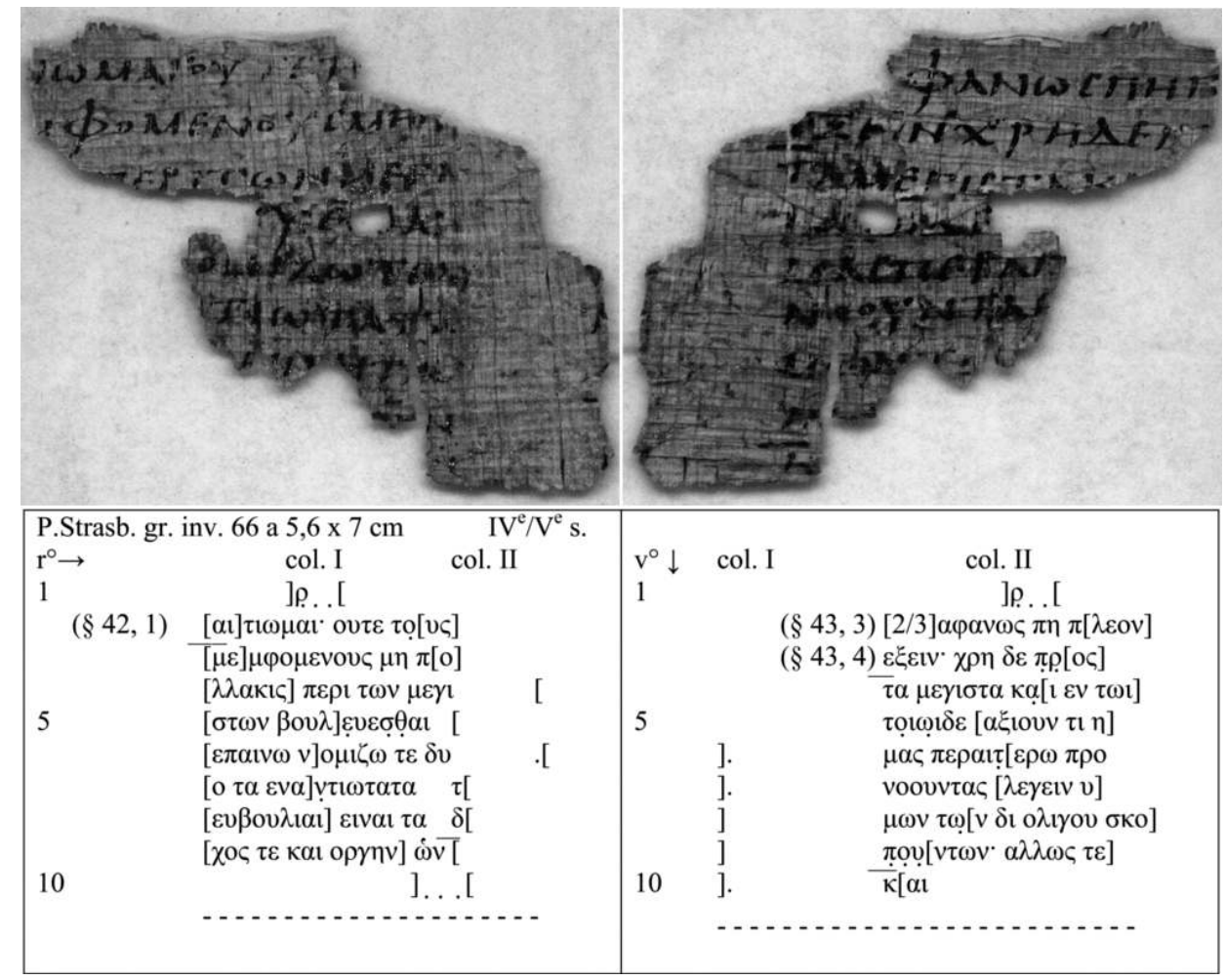

Court mais instructif : un fragment d'une édition de Thucydide, recto et verso (IVe/ve siècle).

(c) Bibliothèque nationale et universitaire de Strasbourg

À première vue, ce fragment (fig. 6) est trop insignifiant pour apporter quoi que ce soit. Il s'agit d'un misérable reste d'une édition du grand historien athénien Thucydide ( $v^{\mathrm{e}} \mathrm{s}$. av. J.-C.) qui ne présente qu'une seule variante, qui plus est déjà connue ${ }^{13}$. Et pourtant, il nous livre des informations intéressantes si on sait ne pas en rester à la surface du texte. Son premier intérêt tient à sa date $\left(\mathrm{IV}^{\mathrm{e}} / \mathrm{v}^{\mathrm{e}}\right.$ siècle). En venant s'ajouter aux papyrus de Thucydide déjà connus datant de l'Antiquité tardive, il nourrit une série assez fournie (de 9 textes) qui fait sens, surtout si l'on tient compte de la raréfaction des papyrus littéraires non chrétiens pendant l'Antiquité tardive et si on la compare au nombre de témoins papyrologiques de l'autre grand historien du canon classique, Hérodote : 


\begin{tabular}{|l|l|l|l|l|l|l|l|l|l|l|l|l|l|}
\hline & III $^{\mathrm{a}}$ & II $^{\mathrm{a}}$ & II/I & I & I/II & II & II/III & III & III/IV & IV & IV /V & V & V/VI \\
\hline Thucydide & 1 & 1 & & 7 & 7 & 29 & 23 & 15 & 1 & 2 & 3 & & 3 \\
\hline Hérodote & & & 1 & 2 & 5 & 14 & 8 & 14 & 1 & 1 & & 1 & \\
\hline
\end{tabular}
d'Hérodote (47), trop accusée pour être le fruit du hasard, montre que le premier était de loin le plus lu des historiens grecs. Thucydide a continué à être copié jusqu'à la fin de l'hellénisme en Égypte, plus que ne le fut Hérodote. Cet intérêt relatif pour Thucydide dont témoignent les papyrus correspond à l'idée que les Anciens se sont faite de cet auteur : modèle d'historien évidemment, mais aussi de rhéteur, à la fois pour les discours qui parsèment son œuvre et pour sa prose en général. Cette dernière qualité suffit à expliquer qu'il ait été si apprécié pendant toute la période impériale et qu'il ait été encore lu dans l'Antiquité tardive, période où la rhétorique triomphe dans tous les domaines et où les œuvres du patrimoine littéraire grec sont elles-mêmes sélectionnées et récupérées comme potentiels manuels d'éloquence. Les principaux ouvrages pratiques de rhétorique comme ceux de Théon, d'Hermogène (ou du Pseudo-Hermogène), d'Aphthonios le citent fréquemment, en lui donnant la préférence sur les autres historiens, et tirent de son œuvre des sujets d'exercices (les progymnasmata ou «exercices préparatoires à la rhétorique »).

Or cette dimension rhétorique de l'œuvre de Thucydide pourrait expliquer la présentation particulière adoptée par le copiste de notre papyrus - et c'est là que je voulais en venir. En effet, ce fragment a la particularité d'appartenir à un codex à deux colonnes par page (même si l'existence d'une seconde colonne n'est garantie que par quelques traces d'encre !). Regardons la liste des codices sur papyrus à double colonne de contenu non chrétien ${ }^{14}$ :

Démosthène II/III Mertens-Pack ${ }^{3} 258.1$

Démosthène II/III Mertens-Pack ${ }^{3} 256.01$

Thucydide II/III Mertens-Pack ${ }^{3} 1516$

Thucydide III Mertens-Pack ${ }^{3} 1509.3$

Eschine III Mertens-Pack ${ }^{3} 3.11$

Anoubion III Mertens-Pack ${ }^{3} 96.01$

Heliodorus medicus ( ?) III Mertens-Pack ${ }^{3} 2376$

Lysias III/IV Mertens-Pack ${ }^{3} 1290$

Isocrate IV Mertens-Pack ${ }^{3} 1251.02$

Démosthène IV/V Mertens-Pack 303.01

Déclamation contre Alcibiade V Mertens-Pack 2497

Catéchisme rhétorique V/VI Mertens-Pack ${ }^{3} 2288$

Démosthène V/VI Mertens-Pack 300.01

On constate, dans cette liste, que les orateurs sont très majoritaires: Isocrate, Lysias, Eschine, Démosthène, une "déclamation", un «catéchisme rhétorique ». Ainsi, il est tentant de conclure à un lien de cause à effet entre le contenu rhétorique et l'emploi de cette forme codicologique pour la littérature profane. Par voie de conséquence, le recours à cette forme pour Thucydide, qui n'est pas un hasard puisque la liste en donne deux autres exemples, nous en dit long sur la conception que les Anciens ont pu se faire de son œuvre, c'est-à-dire la dimension avant tout rhétorique qu'on lui prêtait. Pourquoi telle 
forme était-elle associée à tel type de littérature ? Il y a là un champ d'étude tout à fait nouveau, où la psychologie cognitive aurait sa part à jouer. On voit en tout cas combien la forme d'un livre peut refléter à elle seule la conception que les gens de l'époque se faisaient de l'auteur qu'il contenait, autrement dit combien la bibliologie, loin d'être une donnée contingente, peut être la traduction matérielle de faits culturels. Ce type d'approche mériterait d'être plus systématisé dans les études papyrologiques.

Les papyrus documentaires ont aussi leur mot à dire dans le domaine de la culture écrite, même s'ils sont beaucoup moins exploités à cet égard. Les informations qu'ils livrent sur la langue grecque (et même latine) ont, certes, depuis longtemps retenu l'attention des philologues. On a pourtant voulu frapper le grec des papyrus du sceau du particularisme en le désignant sous l'expression, plus commode qu'exacte, de "grec d'Égypte ». On ne peut bien évidemment nier qu'il ne recèle quelques spécificités, tenant à la fois au substrat indigène, qui génère des interférences, et aux réalités propres au pays - et, de ce point de vue, il est un excellent champ d'observation de l'adaptation d'une langue exogène à un milieu donné sur plus d'un millénaire ${ }^{15}$. Mais, si le grec des papyrus offre de nombreuses particularités par rapport aux sources grecques non papyrologiques (c'est-àdire épigraphiques et littéraires), c'est avant tout parce que le papyrus est le support de textes qui, inscrits dans l'urgence de la vie quotidienne, n'étaient pas nécessairement destinés à la publicité ou à la postérité. Leur langue est tantôt celle qui est parlée dans des milieux fort divers, tantôt celle des bureaux administratifs, et ils roulent principalement sur des sujets concrets. Les papyrus sont donc un bon observatoire du grec « vulgaire » (au sens étymologique du terme) et technique, que les autres sources documentent moins bien. Enfin, contrairement aux inscriptions et aux textes littéraires, ils émanent de tous les milieux alphabétisés et n'ont fait l'objet d'aucune sélection - si ce n'est celle des ravages du temps. Aussi, malgré ses spécificités, le grec des papyrus peut-il être considéré comme s'inscrivant en syntonie avec les autres régions hellénophones dans la dynamique générale que connaît la langue grecque entre la fin de l'époque classique et la période moderne; et, de ce fait, il est susceptible d'apporter un éclairage complémentaire sur le grec usité dans le reste du monde hellénophone en comblant les nombreuses lacunes de la connaissance que nous en avons. Il n'est d'ailleurs pas rare que les papyrus livrent des mots qui nous étaient inconnus du fait de la déficience de nos sources moins périphériques.

29 Les documents contribuent à notre connaissance de la culture écrite non seulement par leur langue, mais aussi évidemment par leur écriture. C'est pourtant un domaine où il reste beaucoup à faire. Il faudrait pour cela sortir des limites trop contraintes et rebattues d'une paléographie qui se cantonne à étudier le développement des écritures, pour scruter les rapports entre écriture et texte, comme le font plus volontiers les spécialistes des textes littéraires ou les médiévistes. Il s'agit d'étudier moins la génétique des écritures que les styles et la mise en page en relation avec, d'un côté, le contenu textuel et, de l'autre, les traditions scripturales des bureaux administratifs locaux. L'existence de styles ou de formats régionaux est en effet une question à peine effleurée. Mais elle n'est pas suffisante. Si les administrations centrales ou locales ont développé des styles graphiques reconnaissables, un même individu (fonctionnaire, notaire ou simple particulier) avait à sa disposition plusieurs styles sur lesquels il pouvait jouer en fonction du type de document qu'il rédigeait ou même de la partie du document qu'il écrivait. En bref, s'il a pu y avoir des styles favoris dans les chancelleries de telle province ou dans les bureaux notariaux de tel district, se sont aussi développés, à la disposition de tous, des 
systèmes de différenciation graphique de nature fonctionnelle variant selon les types documentaires et participant d'une conscience graphique au niveau supra-local de plus en plus prégnante durant l'Antiquité tardive. La recherche dans ce domaine en est encore à ses balbutiements.

Et pourtant, elle est d'une importance considérable pour reconstituer la physionomie concrète de l'écrit quotidien, non seulement en Égypte, mais aussi dans le reste de l'Empire d'Orient, dont les quelques témoins papyrologiques confirment leurs affinités avec les papyrus d'Égypte. Par exemple, le genre épistolaire, très pratiqué et prisé durant l'Antiquité tardive, a suscité de nombreux recueils d'auteurs célèbres (de Libanios à Procope, en passant par Synésios ou Théodoret de Cyr), mais les manuscrits qui nous les ont transmis en ont altéré la forme originale. Seuls les papyrus permettent une archéologie de la lettre qui mette en évidence les décalages - toujours cet art du décalage ! - pouvant parfois exister entre des documents originaux et des textes entrés dans le patrimoine littéraire au prix de quelques aménagements, qu'il n'est pas toujours aisé de repérer lorsqu'on les coupe de leurs conditions concrètes d'élaboration. L'exemple de la lettre n'est pas pris au hasard: une étude de l'épistolographie protobyzantine reste encore à faire, qui ne se limite pas à la seule phraséologie ou rhétorique.

Cette archéologie est d'autant plus importante qu'elle aboutit en fin de compte à montrer en quoi la forme des écrits antiques est conditionnée par les options culturelles de la société qui les produit. Élargie à d'autres aspects formels comme la diplomatique, le lexique et la phraséologie, cette démarche consiste à prendre le document comme champ d'investigation pour une histoire de la culture grecque d'époque protobyzantine. Un exemple concret montrera, j'espère, tout ce qu'elle peut avoir de fructueux et les lumières que les papyrus peuvent jeter sur d'autres types de sources. Le rhéteur Procope de Gaza (vers 465-529) écrit à un de ses anciens élèves, Jérôme, exerçant momentanément en Égypte, une lettre où il tente de se défendre, avec toute l'ironie dont il était capable, des critiques que son correspondant lui a faites dans une lettre précédente :

De quelles accusations, sous des allures modérées, tu nous gratifies, nous l'« arrogant », «trop sophiste » et «maladivement prétentieux»! Et je ne saurais dire tous les reproches que tu as accumulés à notre encontre, comme si tu cherchais depuis longtemps l'occasion de t'exciter la langue contre nous. Du coup, tu n'as même pas saisi un juste prétexte pour étaler toutes les critiques que, sans que je m'en aperçoive, tu gardais cachées depuis longtemps: qu'y a-t-il, dis-moi, d'extraordinaire à ce que, en t'écrivant, je commence ma lettre par «Procope à Jérôme, salut!»? Qu'il s'agisse d'une ancienne règle, je pense que toi aussi, sans doute, tu le reconnaîtras. "Il ne faut en rien, dis-tu, sortir de l'usage en vigueur aujourd'hui. » Dans ce cas, accuse qui voudrait réformer le relâchement qui prévaut de nos jours pour revenir à la noble fierté antique [...]. Pourtant, de ton côté, ayant appris la mollesse égyptienne, tu t'es dépouillé des mœurs de tes ancêtres, toi qui décrètes l'observance des usages, même si c'est hors de propos ${ }^{16}[. .$.$] .$

Tout ce texte pourrait paraître bien abscons et les échauffements de Procope bien dérisoires si l'on ne les replaçait dans le contexte de l'épistolographie du début $\mathrm{du} \mathrm{VI}^{\mathrm{e}}$ siècle telle que nous la documentent précisément les papyrus d'Égypte. Jérôme a reproché à Procope d'avoir eu recours, dans une de ses précédentes lettres, à l'ancien prescrit (formule introduisant la lettre proprement dite) «Untel à untel, salut! » et, par là même, d'avoir placé son nom avant celui de son destinataire contrairement à l'usage qui s'est imposé dans les correspondances privées depuis le $\mathrm{IV}^{\mathrm{e}}$ siècle, à la faveur d'une évolution de la sensibilité et des rapports entre individus, selon lequel on écrit «À untel de la part d'untel, salut!». Si Procope contre-attaque en accusant Jérôme d'être gagné 
par la mollesse égyptienne, ce n'est pas qu'il y aurait une différence de formulaire entre les lettres d'Égypte et celles de Gaza. L'ensemble du texte le montre bien, c'est une question de principe: on doit respecter les usages des anciens Grecs qui, quelles que soient les relations hiérarchiques qu'ils pouvaient avoir avec leurs correspondants, commençaient leur lettre par ladite formule canonique où le nom de l'expéditeur était placé mécaniquement en premier. Ce qui passait aux yeux de Jérôme pour de l'arrogance n'est en fait que du conservatisme. Ce jeu subtil de reproches sur une formule si anodine aurait été difficilement perceptible par le lecteur moderne sans les milliers de lettres originales préservées par les sables d'Égypte, alors même que les lettres de Procope, comme celles des autres écrivains dont les correspondances ont été conservées par la tradition médiévale, n'ont plus leur prescrit original ou sont dotées de prescrits remaniés. L'exemple montre de surcroît combien le formulaire d'un document comme la lettre, même dans ce qu'il a de plus figé, est un miroir des mentalités et des conceptions qu'une société se fait de la sociabilité et de ses formes d'expression écrite.

Une conséquence méthodologique découle de ce qui précède. Nous devons faire tomber une fois pour toutes les barrières qui clivent la papyrologie depuis des décennies en la scindant en deux disciplines de plus en plus hermétiques l'une à l'autre: d'un côté, la papyrologie littéraire, qui ressortit à la philologie et à la littérature; de l'autre, la papyrologie documentaire, qui est le domaine des historiens. L'hyperspécialisation partout galopante n'a fait que renforcer le fossé qui les sépare l'une de l'autre, tant et si bien que peu nombreux sont maintenant les papyrologues capables ou désireux de s'intéresser aux deux. Et pourtant, sans aller jusqu'à réveiller les grands spectres du passé (Kenyon, Grenfell, Hunt, Schubart, Vitelli, et plus récemment Turner, tous aussi à l'aise avec les papyrus littéraires qu'avec les documents), force est de reconnaître à quel appauvrissement intellectuel une telle conception nous conduit aujourd'hui! Cette polarité était d'ailleurs étrangère à l'esprit des Anciens : ils désignaient du même nom, bibliothêkê, une bibliothèque de livres (au sens moderne du terme) et un fonds d'archives publiques ; ils rangeaient chez eux leurs livres et leurs documents dans le même espace; enfin, ils n'hésitaient pas à faire se côtoyer livres et documents sur le même support (en réutilisant un document pour copier un texte littéraire dans les parties restées vierges, ou vice versa), ce qui montre une perméabilité beaucoup plus profonde entre ces deux types de texte que nos conceptions modernes ne nous laissent l'imaginer. Ce dialogue entre papyrologie littéraire et papyrologie documentaire, que j'appelle de mes vœux depuis des années, est surtout d'une extrême fertilité méthodologique quand on veut bien prendre la peine de faire interagir ces deux domaines. Comment ? De deux manières.

La première consiste à scruter les papyrus littéraires comme des documents, autrement dit à les replacer dans le contexte historique de leur rédaction (pour les œuvres contemporaines) ou de leur copie et de leur lecture (pour les œuvres transmises par la tradition), et ainsi à les analyser comme des documents d'histoire ou d'histoire culturelle. Cette sociologie de la littérature et des pratiques lettrées n'est pas neuve, quoique peu pratiquée du fait principalement qu'elle se heurte à la difficulté de contextualiser les papyrus littéraires qui, résultant très souvent de trouvailles clandestines, sont malaisément rattachables à des archives ou à des propriétaires-lecteurs. 

documentaires comme des documents culturels. On a en effet trop tendance à limiter le culturel au seul littéraire. Or la culture d'une époque ne se lit pas seulement dans les listes d'ouvrages qu'elle affectionne ou dans les statistiques faites à partir du corpus des papyrus littéraires conservés ; les documents ont aussi leur mot à dire, et ce de plusieurs façons. La première consiste évidemment à tirer parti de leur contenu et des informations qu'ils livrent sur le monde de la culture: les écoles, les pratiques lettrées (copie, circulation des livres), les manifestations culturelles (conférences, récitations, concours) et, plus généralement, l'alphabétisation des populations. L'onomastique, très exploitée pour l'étude des changements religieux, offre, elle aussi, des données encore trop sousestimées sur les modes culturelles: il n'est pas anodin qu'un magistrat de la cité d'Hermoupolis, au début du $\mathrm{IV}^{\mathrm{e}}$ siècle, s'appelle Achille et sa femme Hermione ${ }^{17}$, deux noms bien homériques qui traduisent les réactions identitaires des élites municipales traditionnelles dont l'hellénisme, face à la montée du christianisme, se réclame de plus en plus visiblement des fondamentaux de la culture grecque profane. Plus tard, les chrétiens adopteront eux aussi des noms homériques comme Ulysse, qui fait son apparition au $\mathrm{v}^{\mathrm{e}}$ siècle, et Ménélas au $\mathrm{VII}^{\mathrm{e}}$, montrant le développement pacifique d'un paganisme d'essence culturelle jugé complémentaire de la culture chrétienne. Exploiter le contenu des documents pour faire de l'histoire culturelle est une démarche qui peut paraître aller de soi, et pourtant il a fallu attendre 2012 pour que l'auteur grec le plus lu, Homère, fasse l'objet de ce type de démarche et que je publie ainsi la première étude systématique sur la culture homérique dans l'Égypte gréco-romaine s'appuyant sur les documents ${ }^{18}$.

(a) que revêtent les documents : leur langue, leur phraséologie, leur diplomatique, leur mise en page -j'en ai déjà un peu parlé plus haut avec la lettre de Procope. Obnubilés par le contenu des documents, les papyrologues oublient trop souvent le parti qu'ils peuvent tirer de leur forme. À cet égard, la papyrologie est victime de la surabondance de sa documentation, les éditeurs se focalisant, dans l'urgence de l'édition, sur le message du texte, en laissant de côté des données qui, parce que matérielles ou formelles, peuvent apparaitre comme contingentes, moins intéressantes ou en tout cas moins immédiatement exploitables. Et pourtant, que d'informations peut-on extraire de l'analyse formelle d'une lettre, d'une plainte, d'un contrat ou d'un édit qui mettent au jour, mieux que tous les discours, les conditionnements culturels d'une société en même temps que le profil culturel, voire intellectuel, des individus qui écrivent ! Il nous manque pour cela un manuel de poétique documentaire - j'emploie à dessein une expression qui frise l'oxymore - qui est une de mes ambitions et qui comblerait un vide méthodologique et intellectuel.

37 La combinaison de ces deux démarches - l'analyse historico-sociologique des papyrus littéraires et l'analyse littéraro-culturelle des papyrus documentaires - permet de dégager deux phénomènes qui me semblent caractéristiques de l'Antiquité tardive et qui transcendent les clivages de la documentation : la première est ce que l'on peut appeler la «littérarisation" des documents. De plus en plus nettement, à partir de la fin du $\mathrm{III}^{\mathrm{e}}$ siècle, les lettres, les contrats, les plaintes relevant de cette écriture, quotidienne ou pratique, par opposition à celle des textes littéraires, témoignent, par leur écriture, leur lexique et leur rhétorique, de l'influence de la littérature non seulement chrétienne, comme on peut s'y attendre, mais plus étonnamment profane. On voit ainsi se multiplier les citations d'auteurs (souvent poétiques), se développer un vocabulaire marqué à la fois 
par un retour à l'atticisme et par l'influence de la poésie, se systématiser le recours à une introduction pétrie de rhétorique qui se veut comme un petit morceau de littérature justifiant le texte qui suit, au contenu plus «terre à terre ». Prenons un exemple entre mille avec la conclusion d'une plainte qu'un individu victime, avec ses covillageois, d'un fonctionnaire local et de ses sbires, adresse en 567 au gouverneur de la province de Thébaïde ${ }^{19}$ (fig. 7) :

Nous prenons notre Seigneur Dieu à témoin qu'en hiver, nous nous nourrissons de chicorée et de sorgho et, en été, des déchets (je veux dire des résidus du criblage) et des grains perdus de l'annone ${ }^{20}$, les mangeant sur nos foyers, étant donné que, celle-ci expédiée, il ne nous reste absolument plus rien. Et surtout nous sommes dépouillés des droits qui sont les nôtres en temps de paix, opprimés depuis longtemps par les attaques de ces innombrables bandits, jour et nuit, bandits qui frayent avec les bergers vagabonds qui sont ligués avec eux. Ils pillent et endommagent tous nos biens au détriment du fisc et pour notre plus grande ruine. En effet, nous nous sommes mis à manquer plus gravement encore de pain par leur faute et nous n'avons plus envie de vivre et de supporter de telles audaces commises dans l'illégalité et dans l'impunité, de supporter leurs manières de loups et de prédateurs agissant toujours à la façon de bêtes carnivores. Car de telles créatures, cruelles et sans peur, répandent le sang humain tout comme une personne très imprudente répand à terre de l'eau en pure perte.

Figure 7

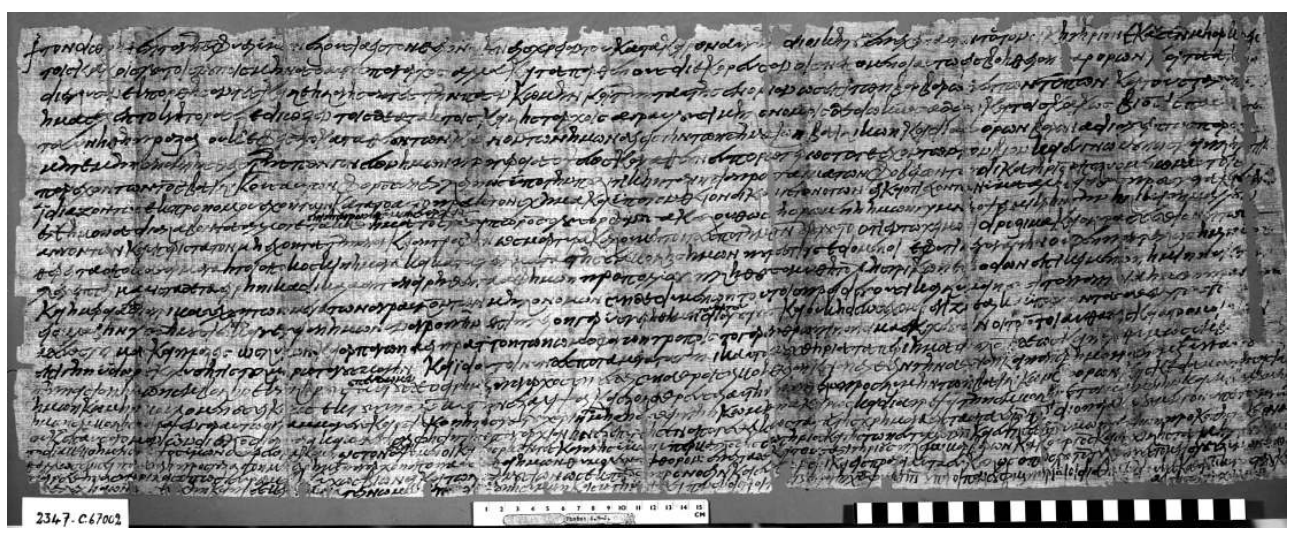

La dernière colonne d'une plainte adressée par un villageois à un gouverneur (567 apr. J.-C.).

(c) Archives photographiques internationales de papyrologie ; photographie : A. Bülow-Jacobsen.

che détresse a priori banal de contribuables qui se plaignent d'être maltraités et de ne plus pouvoir payer leurs impôts, se cache un savant jeu de références à la fois à l'Ancien et au Nouveau Testament, au grand poète grec de l'Égypte protobyzantine, Nonnos de Panopolis, et à Homère, dont une longue comparaison avec des loups carnassiers ${ }^{21}$ est ici paraphrasée de très près. Le divin Homère, maître de l'épopée, mis à profit pour dénoncer des rapines de petits fonctionnaires! Y a-t-il meilleur exemple du prestige de cette antique culture littéraire dans un monde en pleine mutation culturelle?

Il n'y a pas jusqu'à l'écriture qui ne subisse l'effet de ce prestige en étant de plus en plus influencée par les écritures de librairie et en ayant recours à des signes diacritiques propres aux manuscrits littéraires (accents, ponctuation, etc.), de même que la mise en page, jouant sur les blancs, des oppositions de styles et une présentation marquée par les productions de librairies, témoigne d'une attention de plus en plus aiguë au fait graphique et à ses rapports consubstantiels avec le texte. Tout cela traduit les choix d'une 
société qui se fait une haute opinion de la culture littéraire, notamment de la littérature poétique, si bien que celle-ci façonne les modes d'écriture de l'administration et de ses administrés, et que les plus hauts postes de la fonction publique ne sont pas (toujours) donnés à des techniciens du droit ou de l'administration, mais aussi à des hommes de lettres et notamment à des poètes comme Cyrus de Panopolis, devenu préfet du prétoire d'Orient sous Théodose II (qui régna de 408 à 450).

Cette influence de la littérature sur le domaine du document ne s'opère pas à sens unique. Les sources papyrologiques nous donnent à voir un autre phénomène, en sens inverse, que j'appellerais, pour faire pendant à l'expression que j'ai employée tout à l'heure - et en vous priant de m'excuser pour ces vilains néologismes -, la «documentarisation » de la littérature. Dans certains milieux tout au moins, autant qu'on puisse le constater grâce à des dossiers comportant aussi bien des livres que des documents, le patrimoine littéraire se voit en effet conférer une fonction pratique. Loin d'avoir pour (seule) finalité de susciter et d'entretenir le plaisir de la lecture envisagée comme un acte gratuit, certains auteurs deviennent des manuels pratiques d'éloquence ou de rédaction de documents. On a vu que Thucydide passait pour un maître de rhétorique; de même Homère, Ménandre ou Isocrate étaient-ils lus comme des modèles de belle écriture directement exploitables dans les écrits quotidiens.

41 Si le corpus littéraire change de nature et de fonction, il subit aussi une redéfinition de ses limites en s'ouvrant à des genres qui viennent du monde des documents. Le recueil de lettres devient à la mode - j'en ai cité plus haut quelques exemples. Ces textes, à l'origine éphémères documents, gagnent une seconde existence en acquérant le statut de textes littéraires, diffusés comme des manuscrits de littérature auprès d'un lectorat pour lequel ils pouvaient, là encore, servir de modèles potentiellement réutilisables. Les œuvres littéraires contemporaines sont aussi marquées par cette prégnance du document : on se met à écrire des lettres, voire des plaintes en vers, ou on inclut des documents réels ou fictifs dans des œuvres moins circonstancielles à portée littéraire. On élabore des rhapsodies patriographiques ou des recueils hagiographiques, par exemple, en transmutant en littérature tout un matériau documentaire.

Bref, on le voit bien, on ne peut bien comprendre cette interpénétration et ces interactions qu'en ayant une vision complète de la culture écrite, qui ne se limite pas aux seuls textes littéraires, ni ne se cantonne aux grandes figures lettrées, mais qui appréhende l'écrit dans sa globalité selon la même dynamique que celle qui permit aux hommes de l'Antiquité tardive de développer une conception unitaire de l'écrit où création, formation et action interagissaient constamment. Telle sera l'ambition de cette chaire, dont l'intitulé binaire, "Culture écrite de l'Antiquité tardive et papyrologie byzantine ", doit vous sembler maintenant plus clair. Tel sera le défi de mes cours : en s'appuyant sur des inédits, ils tenteront de réconcilier les deux grands domaines de la papyrologie et, à travers eux, l'histoire et la philologie, qui - faut-il le rappeler ? - doivent sans cesse dialoguer pour une compréhension moins biaisée et plus riche de leur objet et qui, plus que jamais, ont besoin de se soutenir mutuellement pour survivre et continuer à nous aider, en aiguisant notre esprit critique et notre lucidité, à recoudre les lambeaux des mémoires passées et à être ainsi le moins possible victimes de nos illusions ou, pire, de celles des autres.

À la mémoire de Gilbert Dagron et d'Antonio Velluto 


\section{ANNEXES}

Les enregistrements audio et vidéo de la leçon inaugurale sont disponibles sur le site du Collège de France : http://www.college-de-france.fr/site/jean-luc-fournet/inaugurallecture-2016-01-07-18h00.htm

\section{NOTES}

1. Ptolémée, fils de Lagos, général d'Alexandre le Grand, lorsque ce dernier mourut en 323 av. J.C., devint satrape, puis roi de l'Égypte (306 ou 305 av. J.-C.), inaugurant la dynastie des Ptolémées (ou Lagides). Celle-ci s'éteindra avec Cléopâtre VII (dite « la Grande ») et la conquête d'Octave en 30 avant notre ère, qui fit de l'Égypte une province romaine.

2. «Papyrus du Musée royal, contenant l'annonce d'une récompense proposée à qui découvrira deux esclaves échappés ", Journal des savants, 1833, p. 329-341 et 477-486; "Papyrus grec du Musée royal, contenant une plainte en violation de sépulture ", Nouvelles Annales publiées par la section française de l'Institut archéologique, vol. I, Paris, 1836, p. 273-285.

3. Émile Egger, De quelques textes inédits récemment trouvés sur des papyrus grecs qui proviennent de l'Égypte, Paris, P. Dupont, 1857, p. 15 (c'est moi qui souligne). Ce mémoire a été lu à la réunion trimestrielle des cinq académies le 7 octobre 1857 et a été réimprimé avec de nouvelles parties dans Émile Egger, Mémoires d'histoire ancienne et de philologie, Paris, A. Durand, 1863, VII (la citation est p. 194).

4. Éditeur du papyrus d'Anastasy («Erklärung einer ägyptischen Urkunde auf Papyrus in griechischer Cursivschrift» dans les Sitzungen der königlich preussischen Akademie der Wissenschaften, Berlin, 1821).

5. Johann Joachim Winckelmann, Geschichte der Kunst des Alterthums, Dresde, Walther, 1764.

6. Daniela Bonanno et Corinne Bonnet, « “Ah! qui dira les torts de l'Égypte...” Lorsque Paul Perdrizet louait les mérites de l'hellénisme à Franz Cumont ", Pallas, $\mathrm{n}^{\circ} 90$ (L'Antiquité en partage. Itinéraires d'histoire et d'archéologie. Mélanges offerts à Jean-Marie Pailler), 2013, p. 91-100 ; mis en ligne le 7 mars 2014, accessible en ligne sur : http://pallas.revues.org/571.

7. Jean Maspero, Papyrus grecs d'époque byzantine. Catalogue général des antiquités égyptiennes du musée du Caire, tomes I-III, Le Caire, 1911-1916.

8. Germaine Rouillard, L'Administration civile de l'Égypte byzantine, préface de Charles Diehl, Paris, PUF, $1923 ; 2^{\mathrm{e}}$ éd. revue, corrigée et illustrée, Paris, librairie orientaliste Paul Geuthner, 1928.

9. Jean Maspero, Organisation militaire de l'Égypte byzantine, Paris, Honoré Champion, coll. «Bibliothèque de l'École des hautes études. Sciences historiques et philologiques » (vol. 201), 1912.

10. André Bataille, Traité d'études byzantines, tome II : Les Papyrus, Paris, PUF, coll. « Bibliothèque byzantine », 1955.

11. Le codex (pluriel : codices) est un ensemble de feuillets pliés et reliés comme un cahier moderne. Supplantant $\mathrm{au} \mathrm{IV}^{\mathrm{e}}$ siècle le rouleau, plus malaisé à manier, il a été le prototype du livre moderne. La minuscule est une écriture cursive réconciliant harmonieusement les principes de lisibilité et d'économie, qui commence à se développer au viI siècle et qui, évinçant les anciennes cursives des documents et les écritures capitales des manuscrits littéraires, traversera le Moyen Âge jusqu'à nos jours, reproduite par la typographie moderne. 
12. Empédocle ( $\mathrm{V}^{\mathrm{e}} \mathrm{s}$. av. J.-C.) : Alain Martin et Oliver Primavesi, L'Empédocle de Strasbourg (P. Strasb. gr. inv. 1665-1666), Berlin/New York, Bibliothèque nationale et universitaire de Strasbourg, 1999 ; Posidippe de Pella (IV-III ${ }^{\mathrm{e}}$ s. av. J.-C.) : Guido Bastianini et Claudio Gallazzi, Posidippo di Pella. Epigrammi (P. Mil. Vogl. VIII 309), Milan, LED, 2001 ; Artémidore d'Éphèse (II s. av. J.-C.) : Bärbel Kramer, Claudio Gallazzi et Salvatore Settis, Il Papiro di Artemidoro, Milan, Edizioni universitarie di lettere economia diritto, 2008 ; Palladas (IV ${ }^{\mathrm{e}}$ s. apr. J.-C.) : Kevin W. Wilkinson, New Epigrams of Palladas: A Fragmentary Papyrus Codex (P.CtYBR inv. 4000), Durham, North Carolina American Society of Papyrologists, 2012 ; Sappho ( $\mathrm{VII}^{\mathrm{e}}-\mathrm{VI}^{\mathrm{e}}$ s. av. J.-C.) : Dirk Obbink, « Two new poems by Sappho ", Zeitschrift für Papyrologie und Epigraphik, nº 189, 2014, p. 32-49.

13. Je l'ai édité dans « Un papyrus strasbourgeois inédit de Thucydide, III, 42, 1 ; 43, 3-4 », Ktèma, $\mathrm{n}^{\circ} 27,2002$, p. 65-70.

14. Je m'appuie sur Eric G. Turner, The Typology of the Early Codex, Philadelphie, University of Pennsylvania Press, 1977, p. 36. Je cite les papyrus d'après le numéro qu'ils ont dans la base des papyrus littéraires de Mertens-Pack ${ }^{3}$, accessible en ligne sur : http://promethee.philo.ulg.ac.be/ cedopal/index.htm.

15. Ce sera un des thèmes de mes premières années de cours sur le multilinguisme: http:// www.college-de-france.fr/site/jean-luc-fournet/_course.htm.

16. Epistolae, 91 dans Procopii Gazaei, Epistolae et declamationes, éd. A. Garzya et R.-J. Loenertz, Studia patristica et byzantina, vol. 9, Ettal, 1963.

17. Ludwig Mitteis, Griechische Urkunden der Papyrussammlung zu Leipzig, Leipzig, Teubner, 1906, document $n^{\circ} 84$, col. III, lignes 9-10.

18. «Homère dans les papyrus non littéraires : le poète dans le contexte de ses lecteurs » dans Guido Bastianini et Angelo Casanova (dir.), I papiri omerici, Florence, Istituto papirologico Girolamo Vitelli, 2012, p. 125-157.

19. Ce papyrus a été publié par Jean Maspero, Papyrus grecs d'époque byzantine, op. cit., tome I, Le Caire, $1911, \mathrm{n}^{\circ} 67002$.

20. Impôt en blé.

21. Iliade, XVI, v. 156-163.

\section{AUTEUR}

\section{JEAN-LUC FOURNET}

Professeur au Collège de France, titulaire de la chaire « Culture écrite de l'Antiquité tardive et papyrologie byzantine » 